\title{
Psychosis and recreational use of MDMA ("Ecstasy")
}

*Eamon Keenan. MB, MRCPsych, Senior Registrar in Psychiatry. The Drug Treatment Centre Board, Trinity Court, 30/31 Pearse Street, Dublin 2, Ireland. Maurice Gervin. MB, Senior House Officer in Psychiatry, Cluain Mhuire Family Centre, Newtownpark Avenue, Blackrock, Co. Dublin. Arthur Dorman, MB, MRCPsych, Registrar in Psychiatry, John J O'Connor, MB, MRCPsych, Consultant Psychiatrict. The Drug Treatment Centre Board, Trinity Court. 30/31 Pearse Street, Dublin 2.

*Correspondence

\begin{abstract}
A seventeen year old man attended the National Drug Treatment Centre with a paranoid psychosis following ingestion of Methylene Dioxy methamphetamine (MDMA). He had been taking MDMA on a recreational basis over a five month period. Although chronic psychosis after heavy use of MDMA has been reported there are no previous reports of psychosis following recreational use. This report highlights the psychological dangers of this drug, which has become widely misused in Dublin over the last two years.
\end{abstract}

\section{Key Words: Psychosis: Methylene dioxy methamphetamine; Recreational use.}

\section{Introduction}

Methylene dioxy methamphetamine (MDMA) is a ring substituted amphetamine derivative chemically related to both hallucinogens and stimulants. It is controlled under schedule 1 of the Misuse of Drug Act 1977. The popular name for this drug is ecstasy because of the "wonderful feeling" it induces in the user.

It was first developed in 1914 as an appetite suppressant but never marketed. It was used in the early 1970's as an adjunct to psychotherapy in the belief that it facilitated therapeutic communication. Despite popular belief between the wars that it was a safe drug, a number of disturbing side effects have since been reported. Henry and colleagues have reported on seven deaths following recreation use of MDMA. (1). The pattern of toxicity included fulminant hyperthermia, convulsions, disseminated intravascular coagulation, rhabdomyolsis, and acute renal failure. He also reported seven cases of hepatotixicity associated with its misuse (1).

Recently in Dublin there has been an upsurge in the use of this drug amongst young people. In 1992, 163 patients presented to our Centre following the use of ecstasy. They were complaining of a variety of psychiatric problems which ranged from panic attacks, anxiety states, paranoid ideation through to full blown psychotic episodes, psychosis, while rare is the most worrying of the problems and has previously been reported in the literature $(2,3)$. The following case describes a chronic paranoid psychosis in a teenager who used the drug on a recreational basis.

This article is a reproduction of that published in: Irish Journal of Psychological Medicine, 10 (3), October 1993, pp. 162-163. Pagination may not match that of original. 


\section{Case Report}

A seventeen year old unemployed male attended the Centre with his mother who had become concerned about his increasingly bizarre behaviour. He gave a history of taking MDMA over a five month period, approximately 1-2 tablets per week at rave parties. He had occasionally taken cannabis but never used opiates intravenously. There was no other history of substance abuse, no previous psychiatric disorder and no family history of psychiatric disorder.

He is the eldest of four boys, his parents having separated when he was aged five. There was evidence of disturbance throughout adolescence as shown by suspension and behaviourial problems at school, trouble with the law since the age of fourteen and poor work record since leaving school at fifteen with no state examinations.

He had last used MDMA, five days previously and almost immediately began complaining of shivers, cold sweats, vomiting, palpitation and disturbing thoughts. His disturbing thoughts had become more persistent over the ensuing days. On prior occasions after using Ecstasy he suffered no adverse consequences.

\section{Mental State Examination}

The patient appeared frightened and had slow deliberate speech. He exhibited paranoid delusions regarding family members and strangers, whom he claimed were watching him and bugging his room. He felt they may be putting unknown substances in his food and he could not trust his friends. He did experience visual hallucinations of balloons and figures in the room and had a feeling that there were "spirits" in his bedroom. He was experiencing third person auditory hallucinations. He also described thought insertion and thought broad-casting. He was complaining of feelings of depersonalisation and ideas of reference regarding the television. A diagnosis of paranoid psychosis was made. He was referred to a psychiatric hospital and commenced on chlorpromazine.

Routine blood investigations and hepatitis screen were normal. A magnetic resonance imaging of the brain was obtained which was normal. Urine screening for all drugs of abuse was negative.

He was discharged from hospital the following day and followed as a day patient for five months. At that time he still exhibited similar symptoms as on presentation i.e. paranoid ideation, intermittent auditory hallucination and passivity phenomena. However these were mush less intrusive and he exhibited no visual hallucinations. He remains on chlorpromazine and his compliance (as reported by family members) seems good. He denies any abuse of MADMA over this period. He admits to smoking cannabis on a few occasions with no worsening of his symptoms.

\section{Comment}

Three cases of chronic paranoid psychosis have been reported in the literature after heavy misuse of MDMA on a daily basis and well in excess of the doses taken by most users $(2,3)$. No previous cases have been reported in subjects taking MDMA on a recreational basis. In fact there have been very few reports overall of psychiatric morbidity related to MDMA use. Although acute paranoid psychosis after substance misuse is well recognised, chronic psychosis is much rarer.

Animal experimentation has shown that MDMA releases serotonin and has dopaminergic actions. At high doses there may be irreversible toxicity to serotonergic neurons in the cerebral cortex and striatum (4). It is suggested that it my have similar effect in humans. Regular users of MDMA may show evidence of impaired serotonergic functions (5).

Chronic psychosis after misuse of MDMA may be due to precipitation of schizophrenia in predisposed subjects however in our patient there was no previous history or family history of psychiatric

disorder. It must be noted that this patient is of an age for onset of major psychiatric illness which may be independent of substance misuse. Also this period of time would not be long enough to exclude the possibility that this is a first episode of schizophrenia or manic depressive psychosis. We feel it is often forgotten that drug misuse in adolescence can be secondary to emotional disturbance. This may be a possible aetiological factor in this particular case. 
In one study profiling recreational users $28 \%$ admitted to problems associated with the use of ecstasy (6). There has been a steady increase in the use of MDMA on a recreational basis in Ireland. While neurotoxic-induced paranoid psychosis has not been fully substantiated we feel that the psychiatric morbidity associated with MDMA is a very worrying complication which warrants further research.

\section{References}

1. Henry JA. Jeffreys KJ, Dowling S. Toxicity and deaths from 3,4 - methylene dioxy methamphetamine ("Ecstasy"). Lancet 1992; 340: 384-7.

2. Creighton FJ. Black DL, Hyde CE, "Ecstasy" psychosis and flash-backs, Br J Psychiatry 1991; 159: 713-6.

3. McGuire P. Fahy T. Chronic paranoid psychosis after misuse of MDMA ("Ecstasy"). BMJ 1991; 302: 697.

4. McKenna DJ, Petrouka SJ. Neurochemistry and neurotoxicity of 3-4 methylene dioxy methamphetamine. J Neurochemistry 1990; 54 (1): 14-44.

5. Price LP, Ricaurte GA, Kyrstel JH, Heninger GR. Neuroendocrine and mood response to I.V. L-tryptophan in MDMA users. Arch Gen Psychiatry 1989; 46: 20-2.

6. Solowij N, Hall W, Lee N. Recreational MDMA use in Sydney a profile of Ecstasy users and their experience with the drug. Br J Addict 1992; 87: 1161-72. 